\title{
THE SCHOOL LIBRARIAN AS INTERNET MEDIATOR:A CASE STUDY AND EVALUATION
}

\author{
James E Herring, Acting Head \\ Department of Communication and Information Studies \\ Queen Margaret College, Edinburgh EH12 8TS. Scotland \\ Email: j.herring@mail.qmced.ac.uk
}

\begin{abstract}
Case studies can be viewed as either having intrinsic interest or as exploratory studies which can be used by subsequent researchers to inform theory. Case studies are not generalizable to populations, as surveys might be, but are generalizable to theory and may have an impact on the development of theory in areas of research. This particular case study relates to the role of the school librarian as Internet mediator and its findings highlight the value of WWW resources in curricular terms and emphasis the key role taken by the school librarian in identifying and exploiting such resources in co-operation with teachers.
\end{abstract}

\section{INTRODUCTION}

This paper will examine the case study as a research method which can be used by those involved in research relating to school libraries. It will seek to highlight the key issues in selecting the case study as a research method as well as the advantages and limitations of the case study. The second part of the paper will provide an example of a case study carried out in a secondary school in Scotland. This case study sought to explore the role of the school librarian as Internet mediator in the context of a school which has a sophisticated information technology (IT) network, an experienced and technologically up-to-date school librarian and teachers who have an interest in exploiting the Internet, and the World Wide Web (WWW) in particular, for curricular purposes. The case study examines the views of both teachers and librarian in relation to the future use of CD-ROMs which are produced in the school and which contain downloaded WWW sites of curricular interest. The case study does not extend to the use of the CD-ROMs by pupils in the school but seeks to examine the issues which arise when teaching and information professionals work together to seek to create and exploit new curriculum related information sources.

\section{THE CASE STUDY AS A RESEARCH METHOD}

\section{The Intrinsic Case Study}

It is generally agreed that case studies are unique and can never be exactly replicated. Thus a study of the impact of the Internet in one school can be followed by a similar study in another school and while the findings of the two case studies may be almost the same in some aspects, the context of the two studies will always be different. The key issue here is that because a case study can never be replicated does not diminish its worth as a contribution to research or its report as a contribution to the literature. Stake (1995) argues that "We study a case when it itself is of very special interest...Case study is the study of the particularity and complexity of a single case, coming to understand its activity within important circumstances." Thus the uniqueness of a particular case study can itself be a reason for adopting this particular method even where there may be no prospect of studying similar cases in the future or where there may be no opportunity to establish common links with previous case studies. Stake (1995) supports this view by classifying this approach as "an intrinsic case study" and states that researchers "are interested in it[the case], not because by studying it we learn about other case studies or about some general problem, but because we need to learn about that particular case. We have an intrinsic interest in the case." There is an obvious drawback in this kind of case study for researchers in that the use which can be made of this type of case study by other researchers may be limited because of the particular uniqueness of that case. In the context of research in school 
librarianship, it is possible that studying the role of the librarian in a particular school might be done purely for intrinsic interest but this author would argue that the choice of a case study as a research methodology should contain an element of desire on the part of the researcher to place the case study in the context of other research whether that be in the form of case study or survey or other method.

\section{Generalization}

Case studies are unique but they need not be seen as only having intrinsic interest for researchers. Yin (1989) states that a common criticism of the case study method is that it is not possible to generalize from a single case. However, Yin argues that "case studies, like experiments, are generalizable to theoretical propositions and not to populations or universes. In this sense, the case study, like the experiment, does not represent a 'sample' and the investigator's goal is to expand and generalize theories (analytic generalization) and not to enumerate frequencies (statistical generalization)." Fidel (1992) supports this view, stating that "The case study attempts, on the one hand, to arrive at a comprehensive understanding of the events under study but at the same time develop more general theoretical statements about regularities in the observed phenomenon." Stake classifies this approach as "an instrumental case study" and argues that a case study can be used as a way of shedding light on a particular research problem or question. In relation to generalization, Stake states that "We do not choose case study designs to optimize the production of generalizations...but valid modification of a generalization can occur in case study." In the context of school library research, it can thus be argued that a case study should not be used to generalize to populations, e.g., if a case study showed that a particular approach to searching CD-ROMs in one school resulted in a marked improvement in the standard of history assignments amongst 14-yearolds, researchers cannot argue that this approach will necessary produce the same results in all other schools in that particular district or city. On the other hand, the particular approach taken in that school can be cited when discussing the range of approaches which might be taken in searching CDROMs in a theoretical manner. Thus the case study may cause researchers to re-examine the existing theory relating to CD-ROM searching as a result of the case study.

\section{Case Studies and Other Research Methods}

Case studies should not be seen as an inferior method when compared with other research methods. Yin (1989) argues strongly that the case study method has often been judged more by prejudice than analysis and states that "Perhaps the greatest concern has been over the lack of rigor of case study research." Yin defends the case study method by stating that this lack of rigor is more often a reflection of the investigator than the method itself. Yin also states that case studies are often criticized for taking too long to complete or producing a vast amount of data which is difficult to analyze effectively but argues that case studies can be done over a short period of time and the outcome can be a precise and easily understood report. Case studies, Yin continues, should not be confused with other methods such as ethnography or observation. Fidel (1992) argues that case studies are often criticized on the basis of reliability, which is described as "the extent to which repeated employment of the same research instrument, under conditions taken to be constant, produces the same result." Fidel states that while case studies cannot meet this particular definition of reliability, they are not invalid because they meet other research criteria such as having value as exploratory studies or in relation to links with theory.

\section{Identifying Research Questions}

Yin (1989) argues that the researcher's choice of strategy depends upon a number of factors, including the type of research question which is posed, the extent to which the investigator has control over actual events and the degree of focus in the study on contemporary events. Yin states that the case study method is geared mainly towards the "how" and "why" type of questions as opposed to the "where" , "how many" and "how much" questions which are the concern of methods such as surveys. In exploratory case studies, Yin states that "what" questions are also relevant. Stake (1995) argues that "the most difficult task of the researcher is to design good questions, research questions that will direct the looking and the thinking...."

\section{Interviewing}

Case studies, therefore, may be seen to be most useful when the researcher has no control over the events (unlike an experiment), the researcher is studying contemporary events (unlike a history), 
and there is no attempt to generalize to populations (unlike a survey). In designing the case study, the researcher has a number of options in relation to the actual methodologies applied within the case study. Both Yin (1989) and Stake (1995) argue that case studies are normally viewed as employing qualitative methods to address the research questions posed. This does not mean that quantitative data cannot be used in case studies but that, certainly within the educational field, qualitative methods are the norm. The methods cited by the authors above include observation and interviewing. Fidel (1992) used observation as a method because it was the most appropriate way of answering the research questions posed in relation to studying online searching. Stake argues that "Qualitative researchers take pride in discovering and portraying the multiple realities of the case. The interview is the main road to multiple realities" and this author chose the interview as the best method of gathering data in the case study outlined below.

\section{Making Use of Case Studies}

As a research method, the case study can be seen to have limitations such as those outlined above but there are clear advantages to using the case study both for the researchers themselves and for those who will read the research reports. For those who make use of case studies-as part of a literature review for further research or on a more practical level as examples of particular experiences from which some lessons may be learned or new approaches may be gained-the findings of the research will be more or less pertinent according to a number of factors. These factors include the similarity of context, e.g., size of school, number of staff in the library; similarity of experience, e.g., extent of use of the Internet within the curriculum; the focus of the case study, e.g., a particular focus on one area of the curriculum such as geography; and the relationships between the key protagonists in the case study, e.g., the school librarian's involvement in curriculum planning.

\section{Summary}

The above discussion seeks to justify the choice of the case study as a relevant methodology in studying aspects of education. It is recognized that the case study method has limitations related in particular to generalization but it is argued that the case study method has attributes which are not available in other research methods.

\section{THE SCHOOL LIBRARIAN AS INTERNET MEDIATOR: A CASE STUDY}

\section{Context}

The focus of this case study is Linlithgow Academy, a 900 pupil comprehensive school in West Lothian, Scotland. The school's home page on its Website (Linlithgow Academy, 1997) states that the aims of the school are:

- To provide all pupils and staff with the opportunity to achieve their maximum potential;

- To provide a supportive environment in which self-confidence and mutual respect can develop;

- To make learning and working a challenging and enjoyable experience.

The school has one professional librarian who receives voluntary assistance from some parents to help with the administration of the library. The school has been very active in developing an information strategy which includes making links with local companies and universities in order to enhance the IT provision within the school. In terms of Internet provision, the school received a server from Sun Microsystems and a broadband connection from a local cable company, Telewest. The school's home page has been developed by pupils in their final year at school and is coordinated by the IT group in the school. The school librarian is a leading member of this group. The school also received a CD authoring system from Hewlett Packard and decided that the combination of these IT resources could be integrated to produce new, value added curriculum resources for the school by downloading websites (with copyright clearance) and making the selected websites available to pupils in the form of a CD-ROM, initially in the library and in future, via the school network.

In terms of Internet provision, Linlithgow Academy is more advanced than most schools in the U.K., although an increasing number of schools now have home pages or are about to have broadband connections and, to this author's knowledge, it is unique in having a CD authoring system in the school. In other ways, the school is typical in that it follows the same curriculum as other 
Scottish comprehensive schools and is at an early stage in exploiting the Internet as a curricular resource, as are many other schools in the UK and elsewhere. Thus in terms of a case study, the school has some unique aspects but in curricular terms, it is not atypical.

\section{The Focus of the Case Study}

The focus of this case study is the mediation of the Internet in a secondary school and the implications of this mediation for the creation of curricular resources and for the role of the school librarian. It can be argued that mediation of information resources in schools by school librarians and teachers is not new. For example, many school librarians still retain a current newspaper cuttings file despite the fact that they have one or more newspapers on CD-ROM in the library. To produce a newspaper cutting, the school librarian can be seen to have mediated the original information resource, i.e., the newspaper and produced a new, value added resource, i.e., the newspaper cutting which is directly related to a section of the curriculum. Thus while mediation of information resources is not new, mediation of the Internet can be seen as an innovation in the school.

The case study was chosen by the author because of his existing links with the school and the school librarian. As Stake (1995) states "It is not unusual for the choice to be no "choice" at all. Sometimes we are given a case, even obligated to take it as the object to study." It is important to the author that the focus of the case study should not be on the technological aspects of Internet mediation. For example, there is no intention to concentrate on which software package should be used to download websites or on the mechanics of producing CD-ROMs. The author's key interest lies in what follows the acceptance of the idea that the Internet should be mediated in this school, what the issues are in creating this mediated resource and how these issues are viewed by the school librarian and selected teachers in relation to the potential curricular use of this new resource and the current and future role of the school librarian as Internet mediator in the school. This case study ends with the creation of a prototype CD-ROM and does not cover the use of the CD-ROM by pupils in the school. The prototype CD-ROM contains websites related to year 2 (age 13) pupils studying geography and in particular, geographic aspects of rain forests.

\section{The research questions}

Yin (1989) argues that "The heart of the protocol is a set of substantive questions reflecting the actual inquiry" and that there are two characteristics of such questions in case studies, as opposed to other methods such as surveys. The first characteristic is that the questions are posed to the researcher and not to a respondent and the second characteristic is that each question should be accompanied by a list of possible sources of evidence. The second characteristic does not pose a problem in this case study as the sources of evidence are the geography curriculum in year 2, the school librarian and the three geography teachers involved in teaching this area. The research questions posed are the key to any case study as they will influence what is studied, how it is studied, what evidence is gathered and how that evidence is presented. It is interesting to note here that this stage of case study research is the same as the task which teachers and school librarians teach pupils to accomplish when identifying the purpose of an assignment or project (Herring, 1996).

The overall research question can be posed as:

- How will the mediation of the Internet in this form affect the role of the school librarian?

From this overall question, a number of other questions can be identified:

- What is the rationale for mediating the Internet?

- What criteria will be used to select relevant websites?

- How valuable will this new information resource be in relation to existing information resources in the school?

- How do teachers and the school librarian view the future in relation to Internet mediation in the school?

\section{Interviewing}

The main method employed in addressing the research questions was the open-ended interview. Consideration was given to other forms of interview such as the semi-structured type but as the aim was to find out what Yin (1989) terms "the facts of the matter as well as the respondents opinions about events," it was decided that semi-structured interviews would be too restrictive in this particular case. The interviews were carried out at specific times but there were also discussions with 
the teachers and the school librarian about particular issues and these discussions contribute to the findings although the use of such discussions may be criticized as being too subjective in that it is the researcher's version of the respondents views, in a situation where there was no immediate record of the discussions, which is being used.

\section{Research findings}

The findings of the research are briefly outlined below and are presented firstly in relation to the specific questions which were posed and then in relation to the overall research question.

What is the rationale for mediating the Internet? There was general agreement amongst the respondents that the most important rationale for mediation was the nature of the Internet itself. Respondents used terms such as "too vast" , "too much information" , "not enough structure" to describe the Internet. There was also a view that pupils in the early years of secondary school would find non-mediated access to the Internet too difficult to cope with because of the sheer amount of information. One teacher posed the question "What do you think pupils would do if they searched by keyword and found hundreds of hits? I heard of a pupil looking for information on Toronto and finding a quarter of a million hits!" The other main concern was more practical and related to the accessibility of sites and one teacher gave an example of spending much time on preparing worksheets to support a part of the curriculum, identifying a number of relevant sites, taking pupils to the networked workshop and finding that most of the sites could not be accessed on that particular afternoon. It was agreed that if the sites were available on CD-ROM and used in the workshop, the problem of access would not arise. Other concerns stated by respondents related to the amount of time which pupils might need to spend to find relevant information from websites and the fact that pupils would inevitably be tempted to continually widen their searches by following up links from particular sites and thus spend even more time at the computer. The school librarian commented that there was also a fear that pupils would spend so much time searching websites that they would either forget about other information resources or not have enough time to examine alternative sources of information. There was thus overall agreement that the Internet should be mediated and that mediation would ensure that the use of information and ideas gained from websites would be much more closely related to the curriculum if this mediation took place.

What criteria will be used to select relevant websites? The main criteria cited by all respondents was relevance to the curriculum and, from the teachers' point of view, specific relevance to individual parts of the curriculum. It was clear that the teachers saw the potential use of the websites as learning resources to which pupils would be directed via the use of worksheets which would cite the URL of the site or part of the site to be searched. The school librarian, not unexpectedly, took a rather broader view of relevance to the curriculum and argued that while a site might be chosen for a particular part of the curriculum, e.g., a rain forest site for year 2 geography, this did not imply that the site could only be used by the geography teacher or by year 2 geography pupils. The school librarian argued that, as with other information resources in the school, there is potentially multiple use across the curriculum and a rain forest site could be used by a modern studies class examining topical issues in international politics.

The language level of the sites was also cited as being important and it was noted by the teachers in particular that, with classes of mixed ability pupils, technical sophistication of the language had to match the pupils' reading ability. In relation to language level, the teachers implied that the pupils' understanding of the language included their understanding of concepts and ideas expressed by that language. Thus it was seen as very important that when particular sites were used, e.g., rain forest sites, the information resource should match the pupils' existing knowledge as far as possible. There was a danger, one teacher argued, that if pupils found technical terms or concepts with which they were not familiar in the website, this could cause confusion amongst pupils. The school librarian argued that whilst the level of language was clearly important, the use of selected websites might also include presenting pupils with information or ideas with which they were not familiar. The pupils would then use alternative sources to research this information.

The format of the websites was also seen as important, particularly in relation to the use of graphics and text. It was generally argued that pupils approached electronic sources of information 
differently and that experiences with the pupils' use of commercial CD-ROMs in geography suggested that pupils had higher expectations of presentation in electronic sources than in books. One teacher stated that pupils would accept a black and white picture in a book but not on a website even where colour was not a key factor from the teacher's point of view. Linked to this was that pupils in year 2 could not always cope with large amounts of text in a website, whereas pupils at levels 5 and 6 could cope. Thus there needed to be a balance between text and graphics which suited the pupils' reading ability but there was also a factor in terms of attracting pupils' attention to the content of the website, i.e., pupils would be more likely to read the text carefully if it was accompanied by attractive graphics. One teacher argued strongly that pupils were more highly motivated to use sites which had attractive graphics.

How valuable will this new information resource be in relation to existing information resources in the school? While both the teachers and the school librarian saw the website based CDROMs as innovative information resources for the school, there were a number of reservations expressed about the value of the resources. All the respondents agreed that the CD-ROMs should not be seen as potential replacements for existing resources in the classroom and in the school library but as additional and complementary resources. That is, the Internet based resources would be valuable inasmuch as they satisfied a curricular need within geography for the teachers and, where possible, across the curriculum for the school librarian. In many cases, the most suitable resources for pupils to use would remain library-based resources including books, journal articles and commercial CDROMs. In the longer term, as the scope of web-based resources on the CD-ROMs grew, the teachers expressed a view that there might be a greater use of such resources in the geography curriculum but none saw the demise of print-based resources.

The school librarian's view was that the CD-ROMs should definitely be seen as additional resources which should be evaluated in the same manner as all other resources in relation to their value as information resources. The key difference with the CD-ROMs, the school librarian noted, was that they were created within the school and with a particular area of the curriculum in mind. Also, because of the teachers' input to the selection and creation of the CD-ROMs, the school librarian felt that the teachers might feel that, as they had a vested interest in the use of such resources, the CDROMs might be seen as more valuable than other resources.

The major reservation expressed about the value of the new resources by both the teachers and the school librarian was the time needed to create the resources. All agreed that, in order to create curricular resources of real value, there was a requirement for a substantial investment in time in not only selecting the websites for the CD-ROMs but particularly in designing learning experiences for the pupils which involved the use of both CD-ROMs and other resources. There was no doubting the desire of both teachers and the school librarian to be involved in the creation of innovative resources but, as one teacher stressed, given all the pressures on teachers in relation to curriculum development, inservice training and administration, it was difficult to see where the time to create such resources was to come from. The school librarian noted that time had always been a feature in relation to creating resources in schools, whether 
based on print, audio-visual, video or computer-based technologies but felt that the CD-ROMs, in their basic form as a collection of websites, should be much easier to create than other resources such as video.

How do teachers and the school librarian view the future in relation to Internet mediation in the school? The key respondents to this question were the school librarian and the principal geography teacher as their knowledge of IT developments was much deeper than the other teachers. Both agreed that Internet mediation would continue for the foreseeable future and particularly for the lower years of the school. The geography teacher saw the possibility of the CD-ROMs becoming more sophisticated learning packages in the future. Rather than merely containing websites which could be searched, the teacher hoped to see CD-ROMs which could be used independently by the pupils. These CD-ROMs would contain the websites, searchable by keywords as well as URLs as well as guidance from the teacher in relation to the task to be completed. The CD-ROMs would contain what the teacher called "electronic worksheets" which could be interactive, e.g., they might contain help buttons which could help pupils to understand technical terms or concepts. The teacher admitted that this was perhaps an ideal and, as above, the question of time being available to create such was resources was a key issue.

The school librarian is heavily involved with the development of the school's home page and envisaged the future as being in the form of the more sophisticated CD-ROMs cited by the geography teacher. In addition to CD-ROMs or even as a replacement for them, the school librarian saw the use of a school intranet as perhaps being the main vehicle for disseminating Internet mediated resources. The Intranet would be accessible from all parts of the school and could contain websites related to all parts of the curriculum as well as the kinds of learning packages which the geography teacher envisaged as being on CD-ROM. The school librarian noted that the computing department was currently investigating the creation of home pages which would contain material related to teaching a new course within that department. The school librarian's main concern here was that if teachers encouraged pupils to access curricular resources on the intranet from the classroom as well as using networked commercial CD-ROMs in the classroom, pupils would possibly ignore the other information resources available in the library. The geography teacher agreed that intranet developments would impact on the use of resources but saw the integration of at least one computer workshop within the library and it would be from such workshops that pupils would mostly use the intranet and this would be allied to the use of print and other resources.

In analyzing the responses to the above questions, it is possible to return to the overall research question:

How will the mediation of the Internet in this form affect the role of the school librarian? The school librarian's view was that the creation of CD-ROMs with websites which could be used directly within the curriculum did affect the role of the librarian as it added to the range of resources and services offered by the library to teachers and pupils. In one sense, it added another role- of Internet mediator-to the many existing roles but in another sense, this role was merely an extension of the school librarian's existing role as information resource provider and manager within the school. The school librarian's task was to identify appropriate curricular materials in all forms and make teachers aware of these resources as teaching and learning tools in the library or in the classroom. Thus when new information resources are available, such the appearance of commercial CD-ROMs in the past few years, the school librarian's task is to adapt to the existence of these new resources and seek ways of exploiting them. The school librarian remarked that in some schools, exploitation of the Internet has been seen as a way of enhancing the status of the school librarian especially in terms of being seen as an IT expert in the school. In this school, however, the status of the school librarian as IT expert and information resource manager was not in doubt. The most dramatic effect of Internet mediation, in the school librarian's view, was the pressure on time available, given the multitude of other tasks requiring attention in the school library, on the school's IT development committee and in relation to the school's home page development.

In the teachers' view, the role of the school librarian as Internet mediator had, in some cases, made teachers more aware of the curricular role of the school librarian. The main reason for this, one teacher noted, was that the school librarian's initiatives in providing websites directly related to curricular needs had allowed the teacher to rethink parts of the curriculum and how information 
resources could be used by pupils. The teachers were also concerned about pressures on time for themselves and for the school librarian and the principal geography teacher noted that, while the present project dealing with one small section of the curriculum was innovative and therefore well supported, it was difficult to see how one school librarian would cope if demand for school-based CD-ROMs increased dramatically across other areas of the curriculum. Another teacher stated that this project had attracted attention across the school and it was likely that some teachers in other areas of the school would be seeking help from the librarian when previously they had little contact with the library.

\section{CONCLUSION}

This paper has examined the case study as a research method and justified the use of the case study in research in school library and information services. The case study has limitations as a method but does provide an in depth study of particular cases which, while not being generalizable to populations, can be generalizable to aspects of theory. The case study undertaken by the author demonstrates in particular the importance of posing research questions and using open-ended interviews to gather data. The potential use of this case study by other researchers and practitioners will depend on thei particular needs but it is hoped that the author's approach might provide some useful guidelines for subsequent case studies of schools exploiting the Internet as an information resource.

\section{REFERENCES}

Fidel, R. (1992). The case study method: A case study. In Glazier, J and R. Powell (Eds.), Qualitative research in information management. Englewood, CO: Libraries Unlimited.

Herring, J. (1996). Teaching information skills in schools. London: Library Association Publishing. Stake, R. (1995). The art of case study research. London: Sage.

Yin, R. (1989). Case study research: Design and methods. London: Sage. 